\title{
A HUMAN FACTORS APPROACH TO WASTE FORM DESIGN
}

\author{
Michael A. Rodriguez \\ EG\&G Rocky Flats, Inc. \\ P.O. Box 464 \\ Golden, CO 80402-0464 \\ (303) $966-6695$
}

\begin{abstract}
Even in the age of computers and high-tech advancements in data manipulation and storage, a great deal of government and industry still rely on old-fashioned paperwork. In many cases this paperwork is legal documentation required by law. Therefore, the accuracy and completeness of the data on these forms, labels, logs, etc., is extremely important. Correction of numerous errors on many documents quickly becomes very timeconsuming and extremely expensive. The best approach to reducing the number of errors on these forms is to start with the form itself. The current study consists of two experiments and an example of a revised waste form to demonstrate the necessity of careful form design and provide guidance in obtaining accurate information through written solicitation of any kind. In Experiment 1, two differently designed forms were used to solicit the same list of specific information. The data suggest that the more clearly designed form significantly produced more of the specific information required than the form that just listed the questions. Experiment 2, which is to be conducted during the spring semester 1994, is designed to address three specific aspects of form design. The results of this Experiment 2 will be interpreted and presented at the 1994 International High-Level Radioactive Waste Management Conference, May 22-26. Guidelines and examples of form design are given.
\end{abstract}

\section{INTRODUCTION}

Forms are, and will continue to be, a valuable method of gathering data and recording information. Although we are in the age of computers and high-tech advancements in data manipulation and storage, a great deal of government and industry still rely on old-fashioned paperwork. Eventually, all these forms will likely be computerized but they will still be forms that must be completed by someone. In government and industry, especially those that deal with radioactive or hazardous waste, these forms are legal documentation required by law. They are used to record vital information concerning type of waste, amount, hazards, etc. Therefore, the accuracy and completeness of the data on these forms, labels, logs, etc., is extremely important-so important, that many government agencies employ groups of people solely to inspect forms to ensure their accuracy.

Typically, most errors on forms are one of two types: the information is either written down incorrectly or it is omitted entirely. The correction of one such error on a document is relatively simple and somewhat inexpensive. In many cases it may take a couple of people two to three hours to determine the correct information and make the correction. The correction of thousands of errors on many documents quickly becomes very time-consuming and extremely expensive. This can easily translate into many hours of work and hundreds of thousands of dollars. The best approach to reduce the number of errors on these forms is to start with the form itself. If the same types of errors are being made consistently, then a redesign of the form may solve the problem. Any type of informationsoliciting tool (such as forms, surveys, questionnaires, etc.) must be designed with care in order to obtain the intended information. If the information is solicited in an ambiguous manner, it will most likely be incorrect or inaccurate. Consequently, the design of the form is extremely important. A well-designed form will save time and reduce error in both filling out and processing the form (Burgess, 1984). Unfortunately, experimental data directly relating to form design is limited. Generally, studies of psycholinguistics are used to determine the most effective language and, to some extent, the structure of the questions. Human Factors studies provide data about text presentation, readability, contrast, etc. (Gray, 1975), and the flow and regulation of forms is represented in the business literature. However, little experimental evidence exists to support these principles when they are applied to

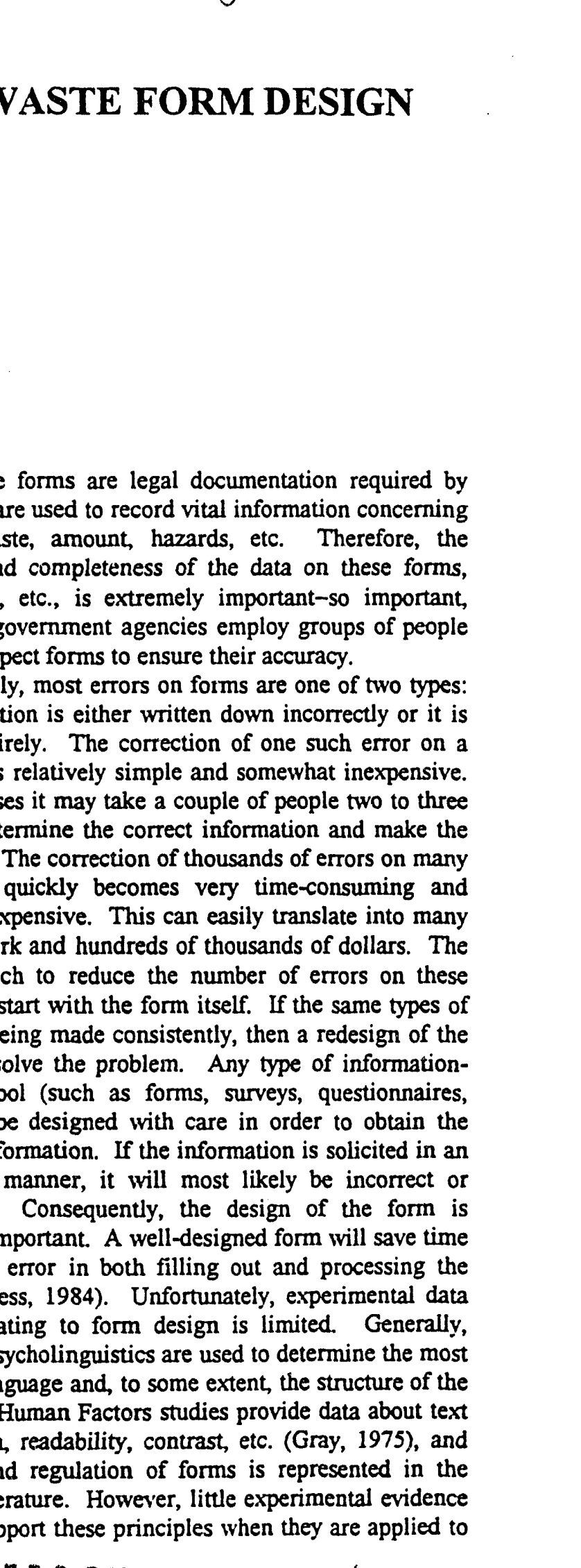


form design.

Form design issues fall into one of three categories: the language on the form, the overall structure of the form, and the substructures within the form such as how the questions are to be answered (Wright, 1980). The current paper consists of two experiments and an example of a waste management form that has been revised to solicit the same information as the original version but in a more specific manner. The goal of this study is to demonstrate the necessity of careful form design and provide guidance in obtaining accurate information through written solicitation. Experiment 1 was conducted during the fall semester 1993 at the University of Colorado, Boulder, Colorado. Experiment 2 will be conducted during the spring semester 1994 also at the University of Colorado. The results of Experiment 2 will be analyzed and reported at the 1994 International High-Level Radioactive Waste Management Conference (May 22-26).

\section{EXPERIMENT 1}

Experiment 1 was designed to demonstrate the necessity of careful form design and provide guidance in obtaining accurate information through written solicitation. Two differently designed forms were used to solicit the same list of specific information. It was hypothesized that the more clearly designed form would produce more of the specific information required than the form that just listed the questions. Success was measurad by how much of the requested information was actually obtained by each form.

Wethod

Subjects. Ten graduate-level students (five males and five females) participated in the study. The students were volunteers from the graduate-level Research Practicum course (Psyc-7051-001) at the University of Colorado, Boulder, Colorado.

Apparatus. The experiment consisted of two different forms (see Appendix 1) designed to obtain the following specific information:

1. Name (first, last, middle initial) with legible spelling.

2. Date (month, day, year).

3. Does subject have a $\mathrm{CO}$ drivers license? (yes/no).

t. How does subject get to campus?

5. Office location (building and room number).

6. Department and program to which the subject has been admitted.

7. Names of two courses enrolled in this semester.

8. What academic year the subject is in.

Form 1 was simply a list of questions and Form 2 was designed to solicit more specific information by phrasing the questions in various manners (see Forms 1 and 2 in
Appendix 1). Form 2 consisted of more detailed questions, some of which provide specific choices for answers. Each subject filled out one form by hand. Each form had eight questions.

Stimuli. The stimuli were the phrasing of the questions on each form to solicit the specific information. The first form was merely a list of questions and the second a more detailed and specific set of questions. Some of the changes made to Form 2 to make it more effective were:

1. Similar information was separated into groups. The educational information was separated from the name, date, and drivers license information. Lines or boxes may also be used for this purpose.

2. Specific answers to questions were provided from which the person completing the form could choose. This may also decrease the time necessary to complete the form. If this format is used all possible answers to the question must be included or an "other" answer must be provided.

3. Exactly what specific information being requested was stated under the blank line or in the question (for example, "Print Name" or "FIRST, MI, LAST").

4. Examples of what information is being requested were given (for example, "1st yr. Grad., etc.").

5. Only common words, phrases, abbreviations, acronyms, etc. were used. Most importantly, these must be common to whoever is going to complete the form.

Procedure. Each subject was given a one-page questionnaire with eight questions to answer. Each subject received either Form 1 or Form 2. The forms were distributed such that the same number of each form would be completed. There was no time limit. The subjects were not permitted to ask questions but were instructed to do their best to answer the question; and turn in the form when it was completed.

\section{Results of Experiment 1}

The number of cases in which the requested information was not obtained was determined for each subject by comparing the completed forms with. the list of specific information needed. The average number of information errors per subject on Form 1 was 3.0 (15 errors total from all Form 1 subjects). The average number of information errors per subject on Form 2 was 0.2 ( 1 error total from all Form 2 subjects). Analysis of variance supported the hypothesis that Form 2 would be significantly more effective in obtaining the specified information, $F(1,8)=32.7, p<.001$ with $\mathrm{MSe}=0.6000$. 


\section{EXPERIMENT 2}

The purpose of Experiment 2 is to test the validity of applying gereral principles obtained from the experimental data of related literature to the design of forms. Specifically, Experiment 2 is to address the three issues of form design mentioned previously, language on the form, overall structure, and substructures within the form. Each variable will have two manipulations resulting in eight different forms and a $2 \times 2 \times 2$ experimental design. To assess the effect of language, one of the following statements will appear at the top of each form: "Complete this form in ink" or "Do not use pencil when completing this form". The first statement is in agreement with forms design literature in that it is affirmative, short, unambiguous, and is in the active voice (Caplan, Lucas, \& Murphy, 1983). This statement also begins with a verb as recommended by Wright and Barnard (1975). The second statement is negative, longer, possibly more ambiguous, and does not begin with a verb. To measure the effect of the overall structure, half of the forms will have the questions grouped by type of information, and within groups the questions will be arranged in a logical order (Knox, 1965, Kaiser, 1968, and Burgess, 1984); the other half will be merely a randomly ordered list of the same questions. Finally, to determine the effect of substructure, how a question is to be answered, the question will be asked, "How do you get to campus?" Half of the forms will have specific answers with check-off boxes (quicker and eliminates legibility problems, Burgess, 1984) and the other half will have just the open-ended question and a line to write the answer. The expected results are described below. According to Johnson and Altman (1973) negative statements may be more effective in relating specific instructions to the reader. Although this is contrary to some of the literature, there is evidence to support this concept. They suggest that this may be due to the tendency of readers to interpret affirmative statements as merely a preference rather than a fundamental requirement. Based on this data it is hypothesized that the negatively phrased statement will result in greater compliance than the positively phrased statement; the more logically arranged form will produce more of the specific information requested and take less time to complete than the form that just lists the questions; and the question with specific answers will provide more useful information than the open-ended version. Success will be measured by how much of the requested information is actually obtained and how long it takes to coinplete each form.

Method

Subjecis. Forty undergraduate-level students (20 males and 20 females) from the University of Colorado, Boulder, Colorado will participate in the study. The students will participate as partial credit of the Introductory Psychology course.

Apparatus. The experiment will consist of eight different forms (see Appendix 2) designed to obtain the following specific information:

1. Name (printed).

2. Date (month, day, year).

3. Student $\mathrm{D}$ number.

4. Date of birth (month, day, year).

5. Place of birth (city/state).

6. Academic year (Freshman, Sophomore, Junior, Senior, Other).

7. Major field of study.

8. Minor field of study.

y. Course requiring participation in this experiment.

10. How does subject get to campus?

11. Does subject plan to attend graduate school? Yes/No

12. Does subject have workstudy experience in their field? Yes/No

13. Has subject begun looking for a job? Yes/No

14. After graduation, what kind of work would the subject like to do?

15. Where would the subject like to work (i.e., city, state, country, etc.).

16. Subjects are requested (in one of two ways) to complete the form in ink.

Stimuli. The three stimuli are the use of either a positive or a negative statement to tell the subject to complete the form in ink, the overall design of the form, and the way in which the transportation question is answered (open-ended or specific choices).

Procedure. Each subject will be sat at a table with a container of pens and pencils (both mechanical and ordinary pencils) and given a 1-page questionnaire with 15 questions to answer. Each subject will receive only one form. The forms will be distributed such that the same number of each form will be completed. There will be no time limit but the time each subject takes to complete the form will be measured and recorded. The subjects will not be permitted to ask questions but will be instructed to do their best to answer the questions and turn in the form when it is completed. Subjects will be told that the completion of the form is preliminary to doing the actual experiment when in fact, the form completion is the experiment.

\section{REVISION OF A WASTE FORM}

One waste form was reviewed and revised to solicit the same information as the original form but in a more specific manner. It is hypothesized that the more clearly designed form will elicit more of the specific information 
required than the previous version of the form. The Human Factors Engineering group at EG\&G Rocky Flats has reviewved many waste forms and provided suggestions about how to improve their effectiveness. One example is the review of the Satellite Area Weekly Inspection Log Sheet (See Appendix 3 for old and new forms). In order to obtain more accurate information at the time of its completion, the following changes were made:

1. The format was changed from five weekly checks per sheet to one weekly check per sheet.

2. Information is separated into different sections for location, questions and comments.

3. Questions were reworded for clarity and capitalization is used to emphasize important words and phrases.

4. Three specific answers are provided to choose from to prevent other types of responses.

5. "Helpful hints" will be included on the back of the form to clarify ambiguity with any of the sections on the front. Ambiguities identified during the walkdown will be used to develop the helpful hints.

6. The form will then be reviewed to ensure that the intent of each question has been preserved.

7. The form will then be walked down with people that will actually use the end product and their comments, if any, will be considered.

8. Questions will be arranged to follow the sequence of events in completing the form as it has been determined from the walkdown.

9. Reviews and walkdowns continue until all personnel involved are in agreement about the intent, format, and meaning of the form.

\section{DISCUSSION}

In order to obtain information through the use of written solicitation, one must first decide exactly what information is necessary. Then the right questions must be asked in the proper manner in order to acquire this information accurately (Burgess, 1984). The design of the form and the phrasing of the questions are extremely important steps. If a question is not clearly understood by those completing the form it is likely that the question will not be answered correctly and the information will have to be obtained in some other way. The waste of time and resources is avoidable by using a well-designed form.

Other manipulations that may be used to improve the usefulness of a form include: type size, type font, page layout, color coding (Pastoor, 1990), shape coding (Rodriguez, 1991), etc. As has been shown in Experiment 1 , there can be a significant difference in the accuracy of information obtained depending on the design of the form and the phrasing of the questions. In many cases this information is time-consuming and expensive to obtain, and therefore, it is extremely important to acquire accurate data up-front. Initially, a well-designed form, questionnaire, or survey will require more resources to design but will result in more accurate and useful data, making it well worth the effort.

The immediate results of this approach to form design will be the increased involvement of the end users in the layout and wording of these forms. This involvement will result in a more user-oriented product and, consequently, a decreased number of errors when completing the forms. The long range results of reducing the number or errors that must be corrected means that resources previously allocated to do this task can now be used to do other work. The accuracy of waste forms, labels, logs, etc., is just as important, if not more so, from a standpoint of complying with State and Federal laws and regulations. When a company is spending hundreds of thousands of dollars per year correcting these types of errors any reduction in their frequency is going to be cost effective and make the upfront design process invaluable.

\section{REFERENCES}

1. Burgess, J.H. (1984). Human factors in forms design. Chicago: Nelson-Hall.

2. Caplan, S.H, Lucas, R.L., \& Murphy, T.J. (1983). Chapter IV, Information Transfer. In Ergonomic Design for People at Work (vol. 1). NY: Von Nostrand Reinhold.

3. Gray, M. (1975). Questionnaire typography and production. Applied Ergonomics, 6,81-89.

4. Johnson, D. \& Altman, H. (1973). Effects of briefing card information on passenger behavior during aircraft evacuation demonstrations. In 17th Annual Proceedings of the Human Factors Society, Santa Monica, CA: Human Factors Society.

5. Kaiser, J.B. (1968). Forms design and control. Connecticut: American Management Association, Inc.

6. Knox, F.M. (1965). Design and control of business forms. NY: McGraw-Hill.

7. Pastoor, S. (1990). Legibility and subjective preference for color combinations in text. Human Factors, 32, 157-171.

8. Rodriguez, M.A. (1991). What makes a waming label salient? In 35th Annual Proceedings of the Human Factors Society, (pp. 1029-1033), Santa Monica, CA: Human Factors Society.

9. Wright, P. (1980). Strategy and tactics in the design of forms. Visible Language, 14, 151-193.

10. Wright, P. \& Barnard, P. (1975). Just fill in this form-a review for designers. Applied Ergonomics, 6, 213-220. 
Form 1 - Expt 1

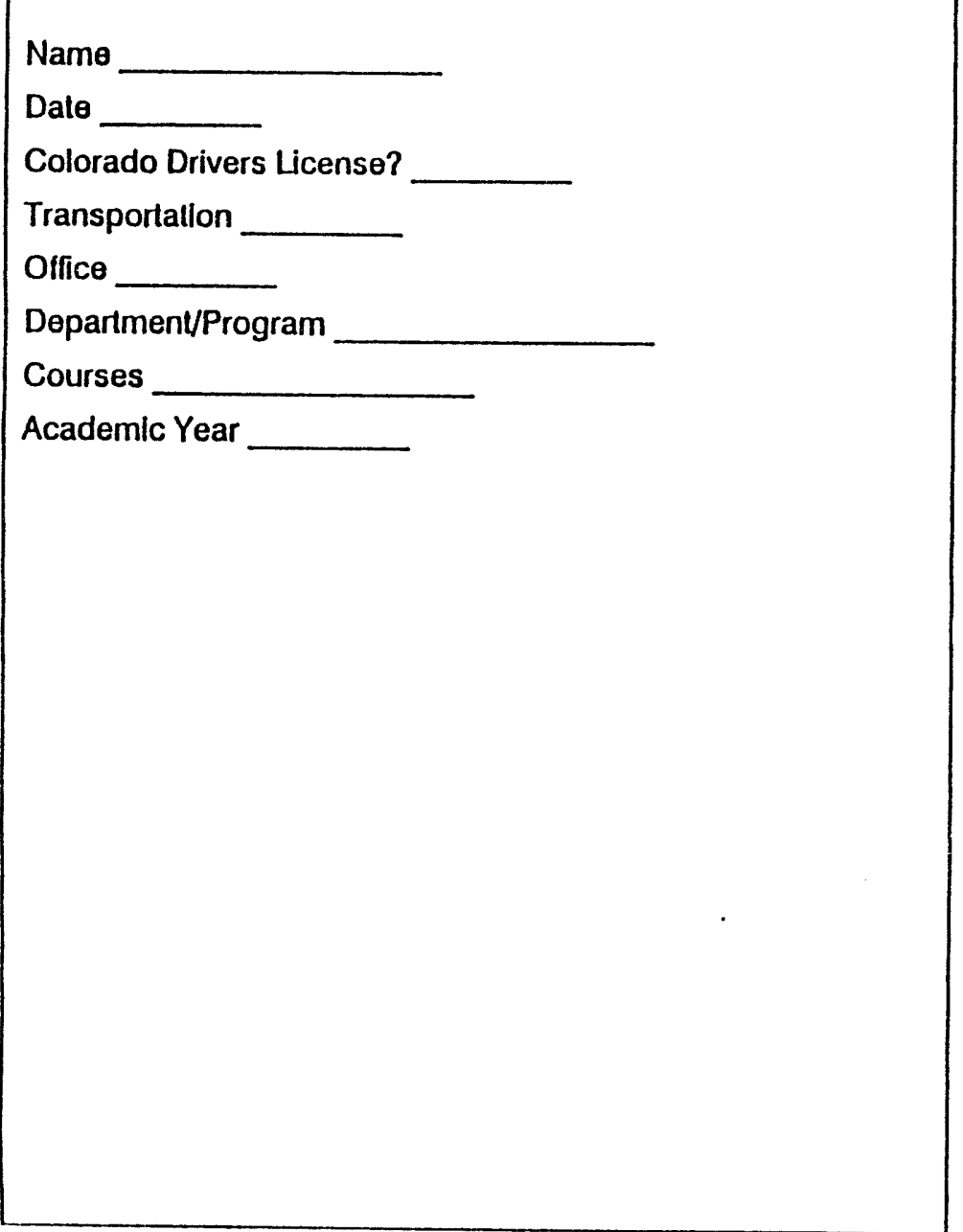

Form 2 - Expt 1

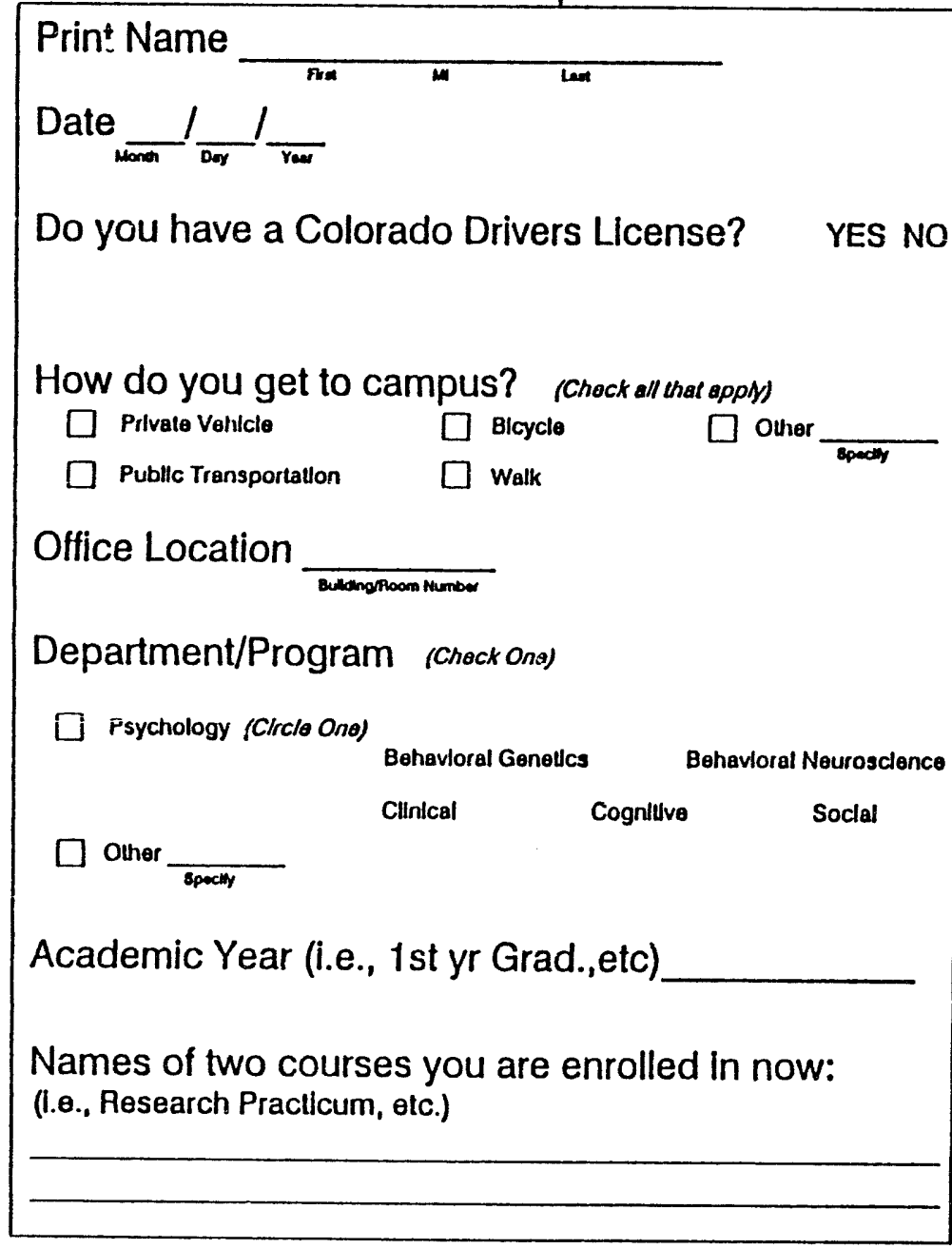



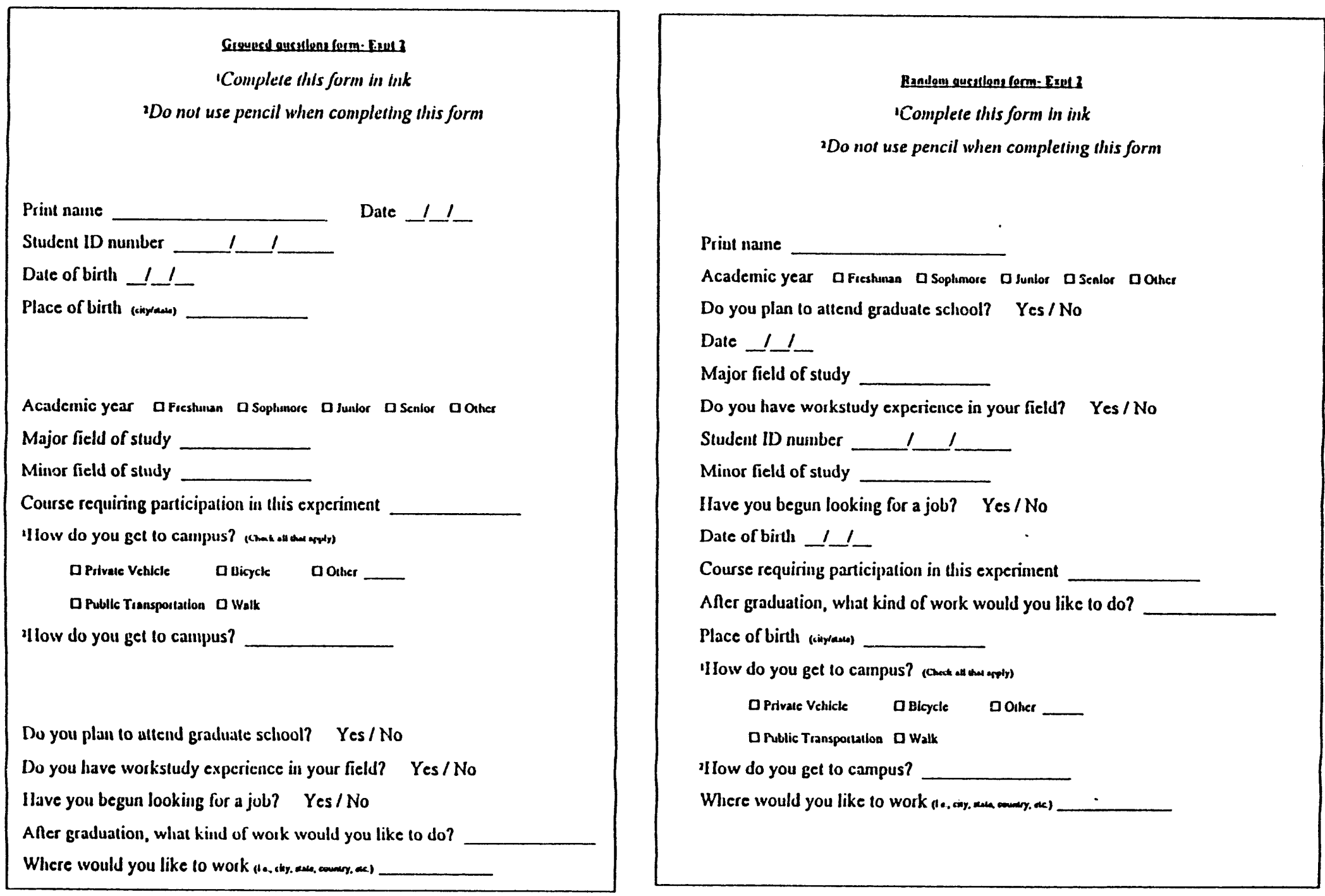
Old Version

HAZARDOUS WASTE MANAGEIMENT

SATELLITE AREA WEEKLY INSPECTION LOG SHEET

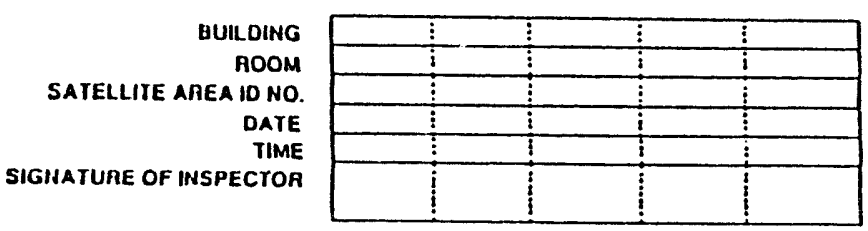

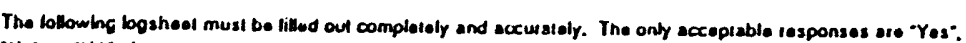

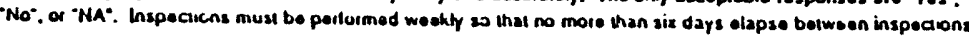
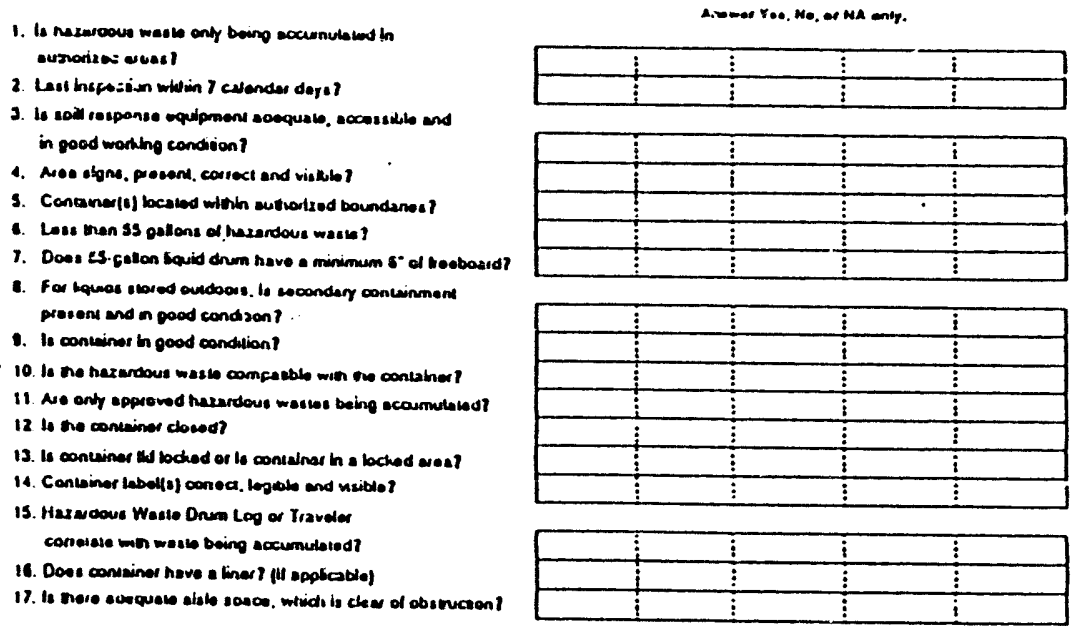

- inspect the contalnar lor holes, denis, butoes, tuas damaged soams or alons of leakago.

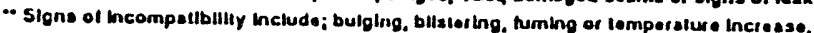

\section{gemsminintions}

ALWAYS MONFY SUPEAVISOR OF ANY PROB:EMS

'WO' AHSWEAS AEOUIRE EXPUUAAIION ANC.OR CORAEC TIVE ACTION IN THE COMMENTS SECTION

COMMENTS ONA CORAECTIVE AC COOIS:

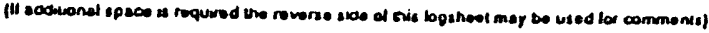

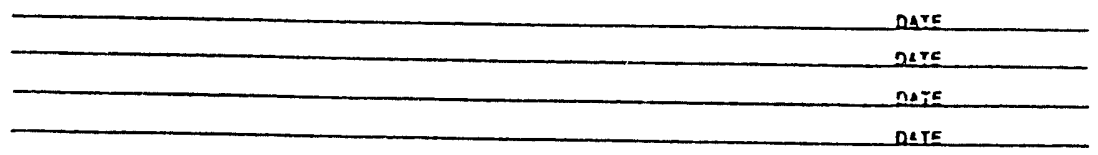

DAIE
Neiv Version

Hazardous Waste Management

Satellite Area Weekly Inspection Log Sheet

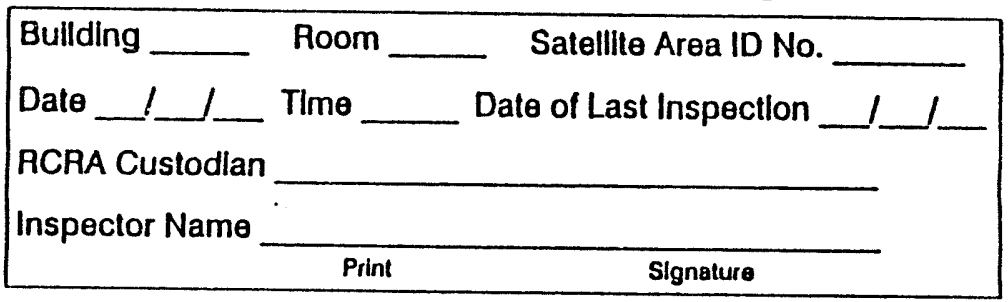

1. Is hazardous waste ONLY In APPROVED CONTAINERS?

2. Was the LAST INSPECTION WITHIN 7 CALENDAR DAYS?

YES NO N/A

3. Is appropilate SPILL RESPONSE EOUIPMENT accossible?

YES NO N/A

YES NO N/A

4 . Is the area ADEQUATELY POSTED?

6. Are the contalners WITHIN AUTHORIZED BOUNDARIES?

YES NO N/A

6. Is there LESS THAN 55 GALLONS of hazardous waste?

YES NO N/A

YES NO N/A

7. Is there AT LEAST 6. of FAEEBOARD in 55-gallon llquid drums?

8. For llquids stored outdoors, Is SECONDARY CONTAINMENT

PRESENT and In GOOD CONDITION?

9. Is the contalner FREE OF RUST, DAMAGE, LEAKAGE, Etc?

10. Is hazardous wasie in APPROPRIATE CONTAINERS?

11. Are only APPROVED HAZARDOUS WASTES beling accumulated?

1c. Is the CONTAINER CLOSED?

13. Is the CONTAINER LOCKED or In a LOCKED AREA?

YES NO N/A

14. Are contalner LABEL(s) VISIBLE, LEGIBLE AND CORRECT?

YES NO N/A

YES NO N/A

YES NO N/A

YES NO NIA

YES NO N/A

YES NO N/A

YES NO N/A

15. Does contalner PAPERWORK SHOW the ACCUMULATED WASTE?

16. Does the container HAVE A LINER? (from traveler)

YES NO N/A

17. Is AISLE SPACE ADEQUATE and UNOBSTRUCTED?

YES NO N/A

Atways notify euporvisor of eny "NOO cosponses.

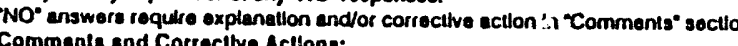

Uso edditional ahools of paper II additlonal space ls iequisod

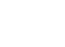

\section{$D_{0}^{0}$ 8 2. $\omega$}

\footnotetext{
FIGURE C. Satelline LCcumulation Area Inspecion Logsneet
} 


\section{DISCLAIMER}

This report was prepared as an account of work sponsored by an agency of the United States Government. Neither the United States Government nor any agency thereof, nor any of their employees, makes any warranty, express or implied, or assumes any legal liability or responsibility for the accuracy, completeness, or usefulness of any information, apparatus, product, or process disclosed, or represents that its use would not infringe privately owned rights. Reference herein to any specific commercial product, process, or service by trade name, trademark, manufacturer, or otherwise does not necessarily constitute or imply its endorsement, recommendation, or favoring by the United States Government or any agency thereof. The views and opinions of authors expressed herein do not necessarily state or reflect those of the United States Government or any agency thereof. 


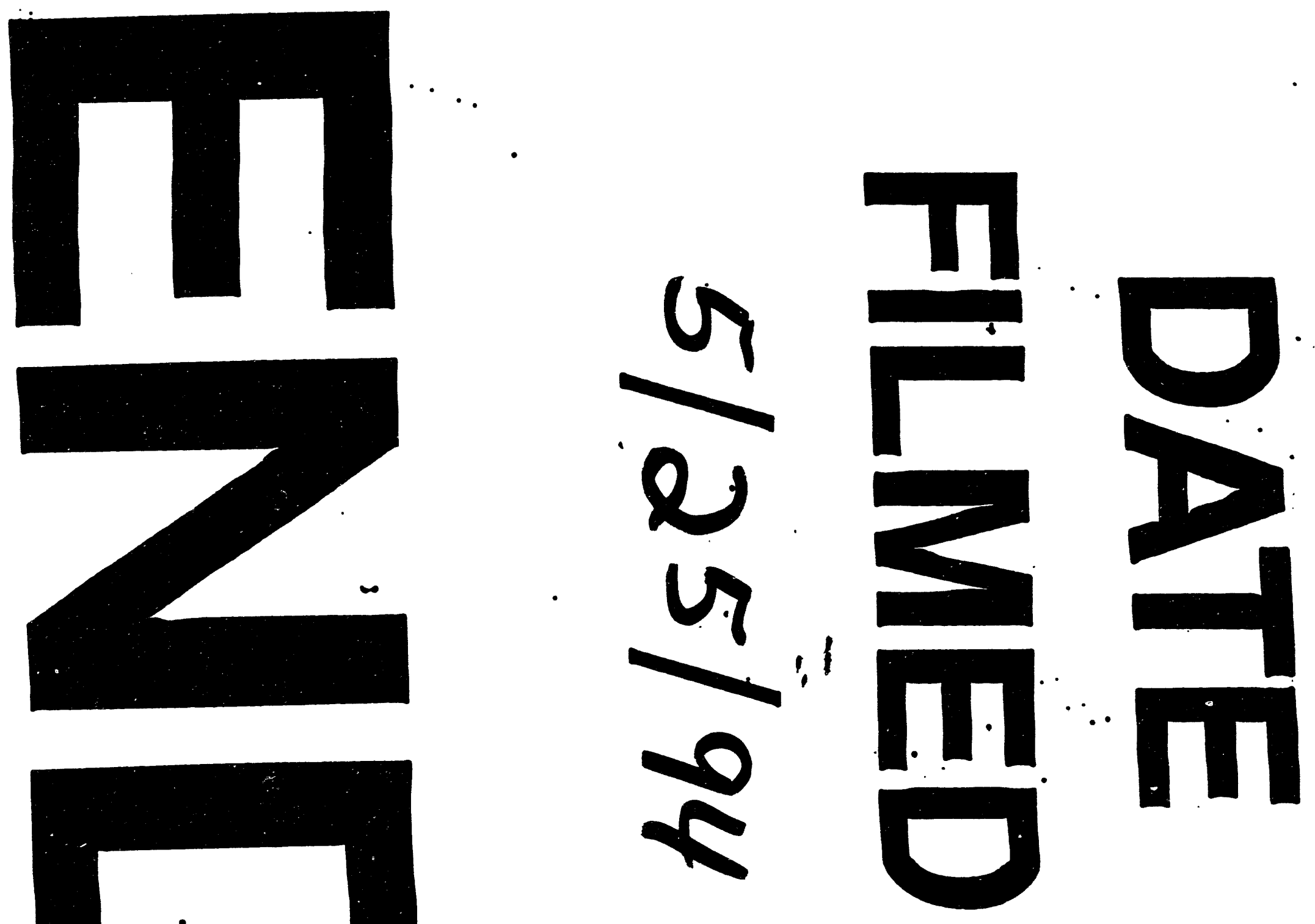


